\title{
PENGARUH CITRA MEREK, DIFERENSIASI PRODUK DAN POSITIONING TERHADAP PROSES KEPUTUSAN PEMBELIAN DI HOTEL BINTANG 4 DI KOTA BANDUNG
}

\author{
Ratih Pitria Purnamasari \\ Sekolah Tinggi Pariwisata Bandung \\ Email:rfitriap@gmail.com
}

How to cite (in APA Style): Purnamasari, R.P. (2018). Pengaruh citra merek, diferensiasi produk dan positioning terhadap proses keputusan pembelian di hotel bintang 4 di kota Bandung. Barista: Jurnal Kajian Bahasa dan Pariwisata, 5(2), Desember 2018, 191-202.

\begin{abstract}
Abstrak: Munculnya berbagai merek baru dalam perkembangan bisnis hotel di Kota Bandung membuat supply untuk akomodasi di Kota Bandung menjadi meningkat. Namun, apabila supply tersebut tidak didukung oleh demand yang meningkat juga, tentunya hal tersebut akan berdampak pada berkurangnya tingkat hunian pada masing-masing hotel. Penelitian ini bertujuan untuk mengkaji aspek citra merek, diferensiasi produk, positioning dan proses keputusan pembelian yang terjadi di Hotel Bintang 4 Kota Bandung. Penelitian ini menggunakan metode kuantitatif, dengan pendekatan penelitian deskriptif dan verifikatif. Berdasarkan hasil pengujian hipotesis yang dilakukan secara simultan dan parsial dinyatakan bahwa seluruh variabel independen yaitu citra merek (X1), diferensiasi produk (X2), positioning (X3) dinyatakan memiliki pengaruh yang signifikan terhadap variabel dependen yaitu proses keputusan pembelian ( $\mathrm{Y}$ ) yang terjadi di Hotel Bintang 4 Kota Bandung. Melalui perhitungan pengaruh citra merek, diferensiasi produk dan positioning terhadap proses keputusan pembelian secara keseluruhan diperoleh nilai pengaruh sebesar 0,711 atau $71,1 \%$, dan besarnya variabel lain yang mungkin mempengaruhi proses keputusan pembelian (variabel epsilon) adalah sebesar 0,289 atau 28,9\%.
\end{abstract}

Kata Kunci: citra merek, diferensiasi produk, positioning, proses keputusan pembelian.

\section{THE EFFECT OF BRAND IMAGES, PRODUCT DIFERENCES AND POSITIONING TO PURCHASE DECISION PROCESSES IN THE 4 STAR HOTEL IN BANDUNG CITY}

\begin{abstract}
With the emergence of various new brands in the development of hotel business in Bandung City, this course makes the supply for accommodation in Bandung City to be increased. However, if the supply is not supported by increasing demand, it will also affect the decreasing occupancy rate of each hotel. Researchers use quantitative research methods, with descriptive and verifikatif research approaches to discuss problems more deeply, and limit the issues about aspects of brand image, product differentiation, positioning and buying decision process that occurred in 4-Star Hotel in Bandung by conducting surveys and research at 4-Star Hotel located in Setiabudhi Area. Based on the result of hypothesis testing conducted simultaneously and partially stated that all independent variables which are brand image (X1), product differentiation (X2), positioning (X3) stated have significant influence to dependent variable which is buying decision process $(\mathrm{Y})$ in 4-Star Hotel at Bandung City. Through the calculation of the influence of brand image, product differentiation and positioning to the overall purchasing decision process, the value of influence is 0.711 or $71.1 \%$, and the other variables that may influence the purchasing decision process (epsilon variable) is 0.289 or $28.9 \%$.
\end{abstract}

Keywords: brand image, product differentiation, positioning, buying decision process. 


\section{PENDAHULUAN}

Persaingan dalam dunia usaha perhotelan kini semakin ketat. Banyak nama merek (brand) hotel baru yang muncul seiring dengan perkembangan kebutuhan wisatawan akan akomodasi di suatu daerah tertentu. Nama merek sangat penting karena nama merek yang mengaktifkan suatu citra dalam pikiran masyarakat. Menurut Aaker dalam Simamora (2004), citra merek merupakan seperangkat asosiasi unik yang ingin diciptakan atau dipelihara oleh pemasar. Citra merek dapat dikatakan sebagai konsep yang diciptakan oleh konsumen karena alasan subyektif dan emosi pribadinya.

Agar strategi citra merek dapat tercipta, maka pemasar harus dapat meyakinkan konsumen bahwa terdapat diferensiasi yang berarti diantara merek dalam kategori produk ataupun jasa. Pengertian diferensiasi menurut Kotler (2005:347) adalah sebagai proses penambahan serangkaian perbedaan yang penting dan bernilai, guna membedakan tawaran perusahaan tersebut dari tawaran pesaing. Strategi diferensiasi pada hotel dapat dilakukan dengan membuat perbedaan produk hotel kita dengan produk hotel pesaing.

Perusahaan dapat melakukan diferensiasi dengan cara mengenali sumbersumber keunggulan kompetitif yang ada, memiliki ciri pembeda utama yang dimiliki perusahaan, dan memilih posisinya yang efektif di pasar. Positioning adalah tindakan perusahaan untuk merancang produk dan bauran pemasaran agar dapat tercipta kesan tertentu diingatan konsumen, sehingga dengan demikian konsumen segmen memahami dan menghargai apa yang dilakukan perusahaan yang berkaitan dengan para pesaingnya.

Citra merek, diferensiasi produk dan strategi positioning akan menjadi pilihan bagi konsumen dalam menentukan keputusan pembelian kamar hotel. Menurut Kotler (2002), keputusan pembelian adalah tindakan dari konsumen untuk mau membeli atau tidak terhadap produk.
Dengan munculnya berbagai merek baru dalam perkembangan bisnis hotel di Kota Bandung, hal ini tentu saja membuat supply untuk akomodasi di Kota Bandung menjadi meningkat. Namun, apabila supply tersebut tidak didukung oleh demand yang meningkat juga, tentunya hal tersebut akan berdampak pada berkurangnya tingkat hunian pada masing-masing hotel. Lalu munculnya persaingan tidak sehat dengan cara membanting harga.

Penurunan tingkat penghunian kamar masih berlangsung hingga saat ini. Kepala Bidang Statistik Distribusi Badan Pusat Statistik Provinsi Jawa Barat, Dudung Supriyadi mengatakan, pada Bulan Januari 2017 tingkat penghunian kamar Hotel di Jawa Barat mencapai 49,49\%, menurun jika dibandingkan pada bulan Desember 2016 yang mencapai 51,45\%. Tingkat penghunian kamar tertinggi menurut kelas hotel bintang pada Bulan Januari 2017 tercatat sebesar 61,78 \% untuk Hotel Bintang 4 (Empat), diikuti oleh Hotel Bintang 5 (Lima) sebesar $53,55 \%$, Hotel Bintang 3 (Tiga) sebesar $53,38 \%$ dan Hotel Bintang 2 (Dua) sebesar $51,35 \%$.

Kawasan Setiabudhi Bandung, merupakan kawasan yang sangat strategis dan banyak dituju oleh para wisatawan untuk berwisata kuliner, wisata belanja dan atraksi wisata hiburan lainnya. Kawasan Setiabudhi banyak menyediakan sarana akomodasi bagi para wisatawan yang ingin berlibur dan menginap di Kota Bandung. Pembangunan bisnis hotel terutama Hotel Bintang 3 (Tiga) dan 4 (Empat) semakin marak di kawasan ini dengan adanya penambahan pembangunan hotel di tahun 2016 sampai saat ini. Munculnya berbagai merek hotel baru ataupun bertambahnya merek hotel chain di industri perhotelan Kota Bandung tersebut, menyebabkan persaingan yang sangat ketat bagi masingmasing hotel agar dapat menarik pangsa pasar yang mereka tuju. Namun, sesuai data yang dikemukan oleh Kepala Bidang Statistik Distribusi Badan Pusat Statistik Provinsi Jawa Barat di atas, tingkat penghunian kamar tertinggi di Kota Bandung masih dipegang oleh kelas hotel 
bintang 4 (empat). Oleh karena itu, penulis tertarik untuk mengkaji permasalahan dalam bisnis perhotelan yang tengah terjadi sekarang ini terutama mengenai aspek citra merek, diferensiasi produk, positioning dan proses keputusan pembelian yang terjadi di Hotel Bintang 4 yang ada di Kota Bandung terutama di Hotel Bintang 4 (empat) yang ada di kawasan Setiabudhi Bandung, sebagai kawasan wisata yang banyak dikunjungi wisatawan. Berdasarkan hal tersebut, dalam penelitian ini penulis memilih judul yaitu "Pengaruh Citra Merek, Diferensiasi Produk Dan Positioning Terhadap Proses Keputusan Pembelian Di Hotel Bintang 4 Kota Bandung".

Dalam penelitian ini, penulis membatasi permasalahan mengenai aspek citra merek, diferensiasi produk, positioning dan proses keputusan pembelian yang terjadi di Hotel Bintang 4 Kota Bandung dengan melakukan surveI dan penelitian di Hotel Bintang 4 (empat) yang berada di kawasan Jalan Setiabudhi Bandung. Adapun 4 (empat) Hotel Bintang 4 yang penulis ambil sebagai lokasi penelitian diantaranya adalah Banana Inn Hotel, Hotel Regata, Grand Setiabudhi Hotel dan Hotel Mercure Bandung.

Tujuan atas penelitian ini yaitu: (1) Untuk mengetahui citra merek, diferensiasi produk dan positioning serta proses keputusan pembelian di Hotel Bintang 4 di Kota Bandung, (2) Untuk mengetahui adanya pengaruh citra merek terhadap proses keputusan pembelian di Hotel Bintang 4 di Kota Bandung, (3) Untuk mengetahui adanya pengaruh diferensiasi produk terhadap proses keputusan pembelian di Hotel Bintang 4 di Kota Bandung, dan (4) Untuk mengetahui adanya pengaruh positioning terhadap proses keputusan pembelian di Hotel Bintang 4 di Kota Bandung.

\section{KAJIAN PUSTAKA Citra Merek}

Pengertian merek menurut Kotler \& Keller (2007:332) adalah nama atau simbol yang bersifat membedakan (seperti sebuah logo, cap, simbol, lambang, tanda, slogan, katakata atau kemasan) untuk mengidentifikasikan barang atau jasa dari penjual atau pemegang merek (Surachman, 2008:3).

Citra Merek (Brand Image) terdiri dari 2 (dua) komponen yaitu Brand Association atau asosiasi merek dan Favorability, Strenght \& Uniqueness of Brand Association atau sikap positif, kekuatan dan keunikan merek. Konsumen dapat membuat asosiasi merek berdasarkan atribut produk, manfaat produk dan keseluruhan evaluasinya atau sikapnya terhadap merek. Konsumen dapat membuat asosiasi berdasarkan atribut yang berkaitan dengan produk misalnya harga dan kemasan atau atribut yang berhubungan dengan produk misalkan warna, ukuran, desain dan fiturfitur lain. Asosiasi juga dapat diciptakan berdasarkan manfaat produk misalnya seperti manfaat fungsional, manfaat simbolik, atau berdasarkan manfaat pengalaman.

\section{Diferensiasi Produk}

Diferensiasi produk merupakan upaya dari sebuah perusahaan untuk membedakan produknya dari produk pesaing dalam suatu sifat yang membuatnya lebih dinginkan oleh pelanggan. Diferensiasi berarti bahwa suatu produk atau jasa memiliki tidak saja keberbedaan dengan produk atau jasa yang sudah ada, melainkan juga merupakan titik keunggulan yang dibandingkan dan diferensiasi tidak berarti asal berbeda, sehingga kalau sudah berbeda berarti pasti memiliki titik keunggulan yang dimaksud (Kotler, 2005:350). Menurut Kotler (2005:350), diferensiasi produk terdiri dari bentuk (form), fitur (features), mutu kerja (performance quality), mutu kesesuaian (conformance quality), ketahanan (durability), kehandalan (reliability), gaya (style), dan desain (design).

\section{Positioning}

Definisi positioning yang diungkapkan oleh Kotler \& Keller (2007:375) bahwa positioning adalah tindakan merancang tawaran dan citra perusahaan sehingga menempati posisi yang khas (dibandingkan para pesaing) di dalam benak pelanggan sasarannya. Tujuannya adalah 
menempatkan merek dalam pikiran konsumen untuk memaksimalkan potensi manfaat perusahaan. Positioning dapat diartikan sebagai pendapat pertama atau apa yang timbul seketika dalam benak konsumen ketika konsumen memikirkan suatu produk. Atau dengan kata lain, positioning adalah tentang bagaimana suatu merek perusahaan dapat masuk dan menguasai benak pelanggan. Penetapan posisi dimulai dengan produk, yaitu suatu barang, jasa, perusahaan, lembaga, atau bahkan orang. Penetapan posisi bukanlah kegiatan yang pemasar lakukan terhadap produk, melainkan merupakan kegiatan yang dilakukan pemasar terhadap pikiran calon pelanggan sehingga posisi produk dengan tepat dapat ditanamkan di benak pelanggan.

\section{Proses Keputusan Pembelian}

Tahap-tahap proses pengambilan keputusan dalam melakukan pembelian menurut Kotler dan Keller (2009:184) ada 5 (lima) tahap, antara lain: (1) Pengenalan masalah, (2) Pencarian informasi, (3) Evaluasi alternative, (4) Keputusan pembelian, (5) Perilaku pasca pembelian.

\section{METODE}

Penelitian ini bertujuan untuk menganalisa sejauh mana citra merek (brand image), diferensiasi produk serta positioning, mempengaruhi proses keputusan pembelian. Objek penelitian yang menjadi variable bebas atau independent variable yaitu citra merek (X1), diferensiasi produk (X2) dan positioning (X3). Selanjutnya yang menjadi variable terikat atau dependent variable yaitu proses keputusan pembelian (Y). Sebagai unit analisis dari penelitian ini ialah tamu regular di 4 (empat) Hotel Bintang 4 yang ada di kawasan Setiabudhi Kota Bandung, diantaranya adala, Banana Inn Hotel, Hotel Regata, Grand Setiabudhi Hotel dan Hotel Mercure Bandung.

Dalam penelitian ini, jenis penelitian yang digunakan adalah penelitian deskriptif dan verifikatif. Dimana dalam penelitian ini akan diuji apakah citra merek, diferensiasi produk dan positioning berpengaruh terhadap proses keputusan pembelian. Dengan menggunakan rumus slovin dalam tingkat signifikansi $10 \%$, sampel yang digunakan dalam penelitian ini adalah sebagian dari populasi penelitian, yaitu sebanyak 100 orang responden yang merupakan sebagian tamu yang menginap di Banana Inn Hotel, Hotel Regata, Grand Setiabudhi Hotel dan Hotel Mercure Bandung pada periode Februari - Maret 2017.

Uji instrumen yang digunakan dalam penelitian ini yaitu uji validitas dan reliabilitas. Rumus yang digunakan untuk uji validitas menggunakan nilai korelasi skor total yang memakai teknik Korelasi Product Moment. Sedangkan pengujian reliabilitas untuk kuesioner penelitian dilakukan dengan menggunakan rumus Alfa Cronbach. Pengujian hipotesis yang dilakukan yaitu secara simultan dan parsial.

Sebagai langkah untuk memverifikasi hasil pada penelitian ini, makan digunakan analisis jalur (path analysis). Hipotesis yang diajukan yaitu secara simultan dan parsial.

1. Hipotesis secara simultan

Jika $\mathrm{F}_{\text {hitung }}>\mathrm{F}_{\text {tabel, }}$ maka $\mathrm{H}_{0}$ ditolak dan $\mathrm{H}_{1}$ diterima.

$\begin{array}{rlr}\mathbf{H}_{\mathbf{0}}: \mathbf{P}_{\mathbf{y x}}=\mathbf{0} & \begin{array}{l}\text { Tidak terdapat } \\ \text { pengaruh r yang }\end{array} \\ & \text { signifikan antara citra } \\ & \text { merek, diferensiasi } \\ & \text { produk dan positioning } \\ & \text { terhadap proses } \\ & \text { keputusan pembelian } \\ & \text { di Hotel Bintang 4 Kota } \\ & \text { Bandung. } \\ \mathbf{H}_{\mathbf{0}}: \mathbf{P}_{\mathbf{y x}} \neq \mathbf{0} & \text { Terdapat pengaruh } \\ & \text { yang signifikan antara } \\ & \text { citra } & \text { diferensiasi produk } \\ & \text { dan positioning } \\ & \text { terhadap proses } \\ & \text { keputusan pembelian } \\ & \text { di Hotel Bintang 4 Kota } \\ & \text { Bandung. }\end{array}$

2. Hipotesis secara parsial 
Jika $t_{\text {hitung }}>t_{\text {tabel, }}$ dengan nilai signifikansi $<0,05$ maka $\mathrm{H}_{0}$ ditolak dan $\mathrm{H}_{1}$ diterima.

\begin{tabular}{|c|c|}
\hline$H_{0}: b_{1}=\mathbf{0}$ & $\begin{array}{l}\text { Tidak terdapat } \\
\text { pengaruh yang } \\
\text { signifikan antara citra } \\
\text { merek terhadap proses } \\
\text { keputusan pembelian } \\
\text { di Hotel Bintang } 4 \text { Kota } \\
\text { Bandung. }\end{array}$ \\
\hline \multirow[t]{3}{*}{$\mathbf{H}_{0}: \mathbf{b}_{1} \neq \mathbf{0}$} & $\begin{array}{l}\text { Terdapat pengaruh } \\
\text { yang signifikan antara } \\
\text { citra merek terhadap } \\
\text { proses keputusan }\end{array}$ \\
\hline & pembelian \\
\hline & $\begin{array}{lll}\text { Bintang } & 4 & \text { Kota } \\
\text { Bandung. } & \end{array}$ \\
\hline $\mathbf{H}_{0}: \mathbf{b}_{1}=\mathbf{0}$ & Tidak \\
\hline & pengaruh \\
\hline & signifikan \\
\hline & $\begin{array}{l}\text { diferensiasi } \\
\text { terhadap }\end{array}$ \\
\hline
\end{tabular}
keputusan pembelian di Hotel Bintang 4 Kota Bandung.

$\mathbf{H}_{\mathbf{0}}: \mathbf{b}_{\mathbf{1}} \neq \mathbf{0} \quad$ Terdapat pengaruh yang signifikan antara diferensiasi terhadap proses keputusan pembelian di Hotel Bintang 4 di Kota Bandung.

\begin{tabular}{|c|c|}
\hline$H_{0}: b_{1}=0$ & $\begin{array}{lr}\text { Tidak } & \text { terdapat } \\
\text { pengaruh } & \text { yang } \\
\text { signifikan } & \text { positioning } \\
\text { terhadap } & \text { proses } \\
\text { keputusan } & \text { pembelian } \\
\text { di Hotel Bintang } 4 \text { Kota } \\
\text { Bandung. }\end{array}$ \\
\hline $\mathbf{H}_{0}: \mathbf{b}_{1} \neq \mathbf{0}$ & $\begin{array}{lr}\text { Terdapat } & \text { pengaruh } \\
\text { yang signifikan antara } \\
\text { positioning terhadap } \\
\text { proses } & \text { keputusan }\end{array}$ \\
\hline & pembelian di Hotel \\
\hline & $\begin{array}{l}\text { Bintang } \\
\text { Bandung. }\end{array}$ \\
\hline
\end{tabular}

\section{HASIL DAN PEMBAHASAN}

Berdasarkan hasil pengujian validitas dan reliabilitas pada masing-masing variabel dalam model penelitian ini dinyatakan valid dan reliable, karena terbukti bahwa $r$ hitung lebih besar dari $r$ tabel. Oleh karena itu, pernyataan-pernyataan yang ada dalam angket/kuesioner penelitian ini adalah valid dan dapat digunakan untuk mengukur variabel yang diteliti, serta hasil pengukuran dalam penelitian dinyatakan reliable sehingga relatif konsisten walaupun pengukuran diulangi dua kali atau lebih hasilnya akan tetap dapat dipercaya.

Hasil dari pengolahan data statistik, matriks korelasi memperlihatkan hubungan antara variabel citra merek (X1), diferensiasi produk (X2) dan positioning (X3) terhadap proses keputusan pembelian (Y). Berdasarkan hasil uji korelasi antara variabel X1, X2 dan X3 dengan variabel Y secara berurutan yaitu, citra merek $(0,770)$, diferensiasi produk $(0,734)$ dan positioning $(0,791)$. Pernyataan tersebut menegaskan bahwa hubungan antara variabel positioning (X3) terhadap proses keputusan pembelian (Y) merupakan hubungan antar variabel dengan nilai korelasi terbesar yaitu 0,791. Tingginya nilai korelasi antara positioning terhadap proses keputusan pembelian menunjukkan bahwa strategi penempatan posisi hotel sangat melekat dimata dan pikiran pangsa pasar dan hal tersebut akan sangat menentukan proses keputusan pembelian tamu Hotel Bintang 4 di Kota Bandung.

Nilai korelasi terendah antara variabel $\mathrm{X}$ terhadap variabel $\mathrm{Y}$ terdapat pada variabel diferensiasi produk (X2) terhadap variabel proses keputusan pembelian $(\mathrm{Y}$ ) dengan nilai korelasi sebesar 0,734, menunjukkan bahwa dalam proses keputusan pembelian, tamu menentukan pilihannya tidak terpaku kepada produk atau pelayanan hotel yang membedakannya dengan hotel berbintang kelas lainnya.

Hubungan korelasi antar variabel X yang tertinggi terdapat pada hubungan korelasi variabel citra merek dan positioning dengan nilai korelasi sebesar 0,838. Tingginya hubungan korelasi antara citra merek dengan positioning dikarenakan kedua variabel independen tersebut memiliki keterikatan dalam benak konsumen, dimana citra merek untuk posisi hotel dengan level bintang 4 (empat) bermakna positif dan dinilai baik dimata 
konsumennya. Sedangkan hubungan korelasi terendah antar variabel $\mathrm{X}$ terdapat pada hubungan korelasi diferensiasi produk dan positioning dengan nilai korelasi sebesar 0,676. Hal ini menunjukkan bahwa dimata konsumen hotel Bintang 4 adanya perbedaan produk dengan penempatan

\section{Uji Bersama (Simultan)/Uji F}

Untuk dapat mengetahui sejauh mana pengaruh citra merek, diferensiasi produk dan positioning terhadap proses posisi sebagai Hotel Bintang 4 tidak mempunyai hubungan yang signifikan.

Korelasi antara citra merek dan diferensiasi produk terhadap proses keputusan pembelian dapat dikatakan kuat, sedangkan korelasi antara positioning terhadap proses keputusan pembelian dinyatakan sangat kuat.

keputusan pembelian secara simultan (uji F), maka perlu dilakukan pengujian hipotesis, dimana hasilnya dapat diperoleh pada tabel berikut:

ANOVA $^{b}$

\begin{tabular}{|ll|r|r|r|c|c|}
\hline \multicolumn{1}{|l|}{ Model } & \multicolumn{1}{|c|}{$\begin{array}{c}\text { Sum of } \\
\text { Squares }\end{array}$} & df & Mean Square & F & Sig. \\
\hline 1 & Regression & 429.729 & 3 & 143.243 & 78.642 & .000 a \\
& Residual & 174.861 & 96 & 1.821 & & \\
& Total & 604.590 & 99 & & & \\
\hline
\end{tabular}

a. Predictors: (Constant), Positioning, Diferensiasi Produk, Citra Merek

b. Dependent Variable: Proses Keputusan Pembelian

Karena nilai $F_{\text {hitung }} 78,642$ lebih besar dari nilai $\mathrm{F}_{\text {tabel }} 2,70(3 ; 96)$, maka dapat ditarik kesimpulan bahwa variabel citra merek, diferensiasi produk dan positioning secara simultan berpengaruh terhadap variabel proses keputusan pembelian. Hasil dari pengujian hipotesis secara simultan adalah $\mathrm{F}_{\text {hitung }}(78,642)>$ $\mathrm{F}_{\text {tabel }}(2,70)$ tersebut, maka dengan kata lain $\mathrm{H}_{0}$ ditolak dan $\mathrm{H}_{\mathrm{a}}$ diterima, yang artinya secara simultan terdapat pengaruh yang signifikan antara citra merek, diferensiasi produk dan positioning terhadap proses keputusan pembelian di Hotel Bintang 4 Kota Bandung.

\section{Uji Individu (Parsial)/Uji t}

Pengujian secara parsial dilakukan untuk mengetahui tingkat signifikansi dari masing-masing variabel bebas (X) terhadap variabel terikat (Y). Hasil dari pengujian secara parsial dapat dilihat dalam tabel berikut:

\begin{tabular}{|c|c|c|c|c|c|}
\hline \multirow[b]{2}{*}{ Model } & \multicolumn{2}{|c|}{$\begin{array}{c}\text { Unstandardized } \\
\text { Coefficients }\end{array}$} & \multirow{2}{*}{$\begin{array}{c}\text { Standardized } \\
\text { Coefficients }\end{array}$} & \multirow[b]{2}{*}{$\mathrm{t}$} & \multirow{2}{*}{ Sig. } \\
\hline & B & Std. Error & & & \\
\hline (Constant) & 2.728 & 1.624 & & 1.680 & .096 \\
\hline Citra Merek & .106 & .053 & .215 & 2.006 & .048 \\
\hline Diferensiasi Produk & .131 & .033 & .313 & 3.939 & .000 \\
\hline Positioning & .199 & .051 & .399 & 3.872 & .000 \\
\hline
\end{tabular}

a. Dependent Variable: Proses Keputusan Pembelian 
BARISTA: Jurnal Kajian Bahasa dan Pariwisata

p-ISSN 2356-1602 I e-ISSN 2622-5999

Website: http://stp-bandung.ac.id/ejournal/index.php/v01

Diterbitkan oleh Unit Bahasa Sekolah Tinggi Pariwisata Bandung

Nilai konstanta sebesar 2,728 menunjukkan pengaruh positif variabel independen yaitu citra merek, diferensiasi produk dan positioning. Nilai signifikansi dari variabel X1 sebesar 0,048, X2 sebesar 0,000 dan X3 sebesar 0,000 adalah lebih kecil dari 0,05 (5\%). Hasil ini memberikan kesimpulan bahwa variabel citra merek, diferensiasi produk dan positioning berpengaruh signifikan terhadap proses keputusan pembelian.

Setelah $t_{\text {hitung }}$ diketahui, selanjutnya untuk mengetahui nilai $t_{\text {tabel }}$ dengan menggunakan rumus sebagai berikut:

$$
\begin{array}{ll}
\mathrm{t}_{\text {tabel }} & =(\alpha / 2 ; \mathrm{n}-\mathrm{k}-1) \\
\mathrm{t}_{\text {tabel }} & =(0,05 / 2 ; 100-3-1) \\
\mathrm{t}_{\text {tabel }} & =(0,025 ; 96) \gg 1,985
\end{array}
$$

(berdasarkan tabel distribusi nilai tabel)

Hasil pengujian signifikansi dengan menggunakan uji $t$ dilakukan dengan membandingkan $t_{\text {hitung }}$ dengan $t_{\text {tabel }}$. Pengaruh suatu variabel $\mathrm{X}$ terhadap variabel $Y$ dinyatakan signifikan apabila $t_{\text {hitung }}>t_{\text {tabel }}$ dengan nilai signifikansi $<$ dari 0,05 .

PENGUJIAN HIPOTESIS SECARA PARSIAL (UJI T)

\begin{tabular}{|c|l|c|c|c|c|c|c|}
\hline NO & \multicolumn{2}{|c|}{ KOEFISIEN REGRESI } & Thitung & Ttabel & SIG & KEPUTUSAN & KESIMPULAN \\
\hline 1 & Citra Merek & 0,215 & 2,006 & 1,985 & 0,048 & Ho ditolak & Signifikan \\
\hline 2 & $\begin{array}{l}\text { Diferensiasi } \\
\text { produk }\end{array}$ & 0,313 & 3,939 & 1,985 & 0,000 & Ho ditolak & Signifikan \\
\hline 3 & Positioning & 0,399 & 3,872 & 1,985 & 0,000 & Ho ditolak & Signifikan \\
\hline
\end{tabular}

Sumber: Data Olahan, 2017.

Berdasarkan tabel di atas, terdapat variabel X1, X2, dan X3 yang dinyatakan memiliki pengaruh signifikan dalam mempengaruhi variabel $Y$. Hal ini menunjukkan bahwa ketiga variabel independen yaitu citra merek, diferensiasi produk dan positioning sangat berpengaruh terhadap proses keputusan pembelian di Hotel Bintang 4 yang ada di kawasan Setiabudhi Kota Bandung.

Secara keseluruhan, hasil pengujian hipotesis yang dilakukan secara simultan dan parsial dinyatakan bahwa seluruh variabel independen dinyatakan memiliki pengaruh yang signifikan. Oleh karena itu, maka hasil penelitian dapat sepenuhnya dijadikan sebagai acuan jawaban dari hipotesis dalam penelitian ini.

\section{Uji Analisis Path}

Nilai pengaruh langsung dan tidak langsung dalam penelitian ini dapat dilihat

\begin{tabular}{|c|c|c|c|c|c|c|c|}
\hline \multirow{2}{*}{ Variabel } & \multirow{2}{*}{$\begin{array}{c}\text { Koefisien } \\
\text { Regresi }\end{array}$} & \multirow{2}{*}{$\begin{array}{l}\text { Pengaruh } \\
\text { Langsung }\end{array}$} & \multicolumn{3}{|c|}{$\begin{array}{l}\text { Pengaruh Tidak } \\
\text { Langsung }\end{array}$} & \multirow{2}{*}{$\begin{array}{c}\text { Total } \\
\text { Pengaruh } \\
\text { Tidak } \\
\text { Langsung }\end{array}$} & \multirow{2}{*}{$\begin{array}{c}\text { Total } \\
\text { Pengaruh }\end{array}$} \\
\hline & & & $\mathrm{X} 1$ & $\mathrm{X} 2$ & $\mathrm{X} 3$ & & \\
\hline Citra Merek (X1) & 0.215 & 0.046 & & 0.048 & 0.072 & 0.119 & 0.166 \\
\hline $\begin{array}{l}\text { Diferensiasi Produk } \\
(\mathrm{X} 2)\end{array}$ & 0.313 & 0.098 & 0.048 & & 0.084 & 0.132 & 0.230 \\
\hline Positioning (X3) & 0.399 & 0.159 & 0.072 & 0.084 & & 0.156 & 0.316 \\
\hline \multicolumn{7}{|c|}{ TOTAL PENGARUH } & 0.711 \\
\hline
\end{tabular}
dalam tabel berikut:

PENGARUH LANGSUNG DAN TIDAK LANGSUNG

Sumber: Data Olahan, 2017. 
Dalam penelitian ini, variabel X3 yaitu positioning merupakan variabel dengan nilai pengaruh langsung tertinggi yaitu sebesar 0,159 terhadap variabel $Y$ yaitu proses keputusan pembelian. Pengaruh langsung terendah dalam penelitian ini terdapat pada pengaruh antara variabel X1 yaitu citra merek terhadap variabel $Y$ yaitu proses keputusan pembelian dengan nilai sebesar
0,046 . Melalui perhitungan pengaruh citra merek, diferensiasi produk dan positioning terhadap proses keputusan pembelian secara keseluruhan diperoleh nilai pengaruh sebesar 0,711 atau 71,1\%. Maka besarnya variabel lain yang mungkin mempengaruhi proses keputusan pembelian (variabel epsilon) adalah sebesar 0,289 atau 28,9\%.

\section{Model Summary}

\begin{tabular}{|l|r|r|r|r|}
\hline Model & $\mathrm{R}$ & R Square & \multicolumn{1}{|c|}{$\begin{array}{c}\text { Adjusted R } \\
\text { Square }\end{array}$} & \multicolumn{1}{|c|}{$\begin{array}{c}\text { Std. Error of the } \\
\text { Estimate }\end{array}$} \\
\hline 1 & $.843^{\mathrm{a}}$ & .711 & .702 & 1.350 \\
\hline
\end{tabular}

a. Predictors: (Constant), Positioning (X3), Diferensiasi Produk (X2), Citra Merek (X1)

Struktur kausal antara citra merek, diferensiasi produk dan positioning terhadap proses keputusan pembelian dapat dilihat pada gambar berikut:

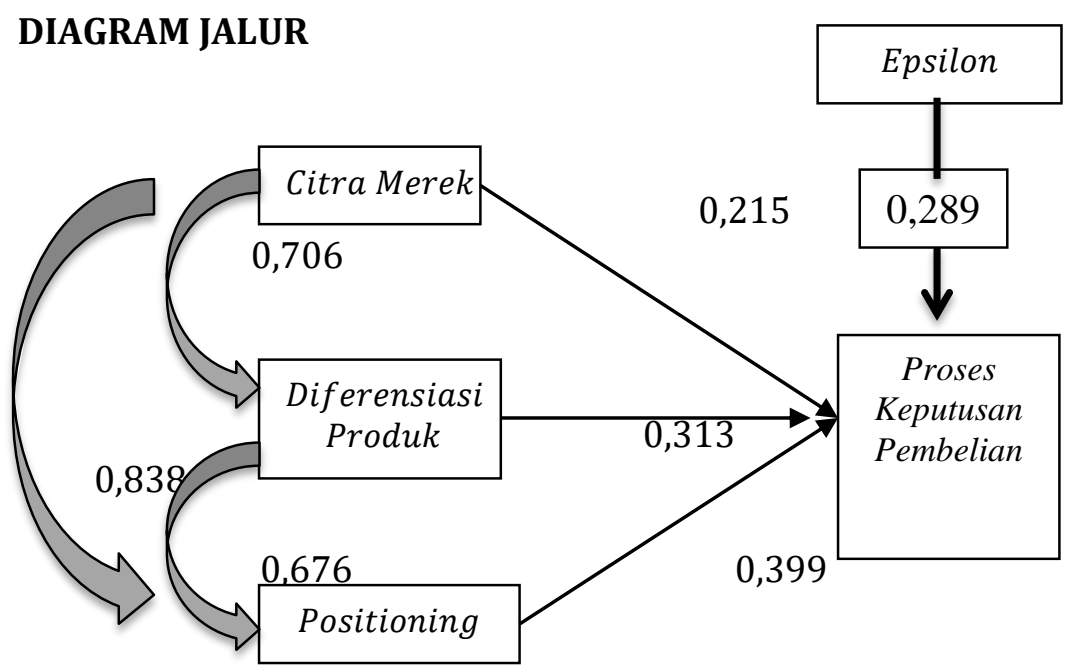

Sumber: Data Olahan, 2017.

Gambar diagram di atas, menjelaskan hubungan antar variabel $\mathrm{X}$ beserta dengan nilai pengaruh masingmasing variabel $\mathrm{X}$ terhadap variabel $\mathrm{Y}$. Dimana hubungan korelasi antara variabel citra merek (X1) dengan diferensiasi produk (X2) yaitu sebesar 0,706, maka dengan demikian hubungan korelasi antara citra merek dengan diferensiasi produk dinyatakan kuat. Hubungan korelasi antara variabel citra merek (X1) dengan positioning (X3) yaitu sebesar 0,838 . Dengan demikian hubungan korelasi antara citra merek dengan positioning dinyatakan sangat kuat. Hubungan korelasi antara diferensiasi produk (X2) dengan positioning (X3) yaitu sebesar 0,676. Dengan demikian, hubungan korelasi antara diferensiasi produk dengan positioning dinyatakan kuat. 
Sedangkan untuk pengaruh masing-masing variabel $\mathrm{X}$ terhadap variabel $Y$ dapat dijelaskan bahwa pengaruh citra merek (X1) terhadap proses keputusan pembelian $(\mathrm{Y})$ sebesar 0,215 atau 21,5\%, diferensiasi produk (X2)

\section{Pembahasan Deskriptif}

Citra merek merupakan aspek yang penting dalam proses keputusan pembelian bagi tamu hotel bintang 4 (empat). Hal ini ditunjukkan berdasarkan tanggapan responden bahwa dalam proses keputusan pembelian, konsumen mempertimbangkan citra positif, kekuatan dan keunikan yang didapat dari suatu merek hotel. Terutama untuk hotel dengan level Bintang 4, yang dianggap memiliki citra yang baik oleh konsumennya.

Diferensiasi produk dalam penelitian ini merupakan aspek yang cukup penting untuk konsumen dalam dalam proses keputusan untuk membeli atau menginap di hotel. Aspek bentuk, fitur, mutu kinerja, mutu kesesuaian, daya tahan, kehandalan, gaya dan desain suatu produk hotel juga menjadi pertimbangan bagi konsumen dalam memutuskan untuk membeli atau menginap. Apalagi ditengah persaingan dengan hotel competitor lainnya yang menawarkan produk dan pelayanan yang hampir sama.

Positioning sebagai hotel dengan level Bintang 4 menjadi hal yang paling penting. Hal ini ditunjukkan berdasarkan tanggapan dari responden, bahwa konsep penempatan hotel, strategi menentukan segmen pasar yang tepat, efektifitas kegiatan pemasaran dan penetapan posisi hotel sebagai hotel Bintang 4 merupakan hal yang paling penting dalam proses keputusan pembelian konsumennya. Terutama untuk hotel Bintang 4 yang berada di Kota Bandung yang mempunyai pesaing yang berbeda-beda jenisnya, tetapi menawarkan produk dan pelayanan yang hampir sama. Penetapan sebagai hotel Bintang 4 akan memberikan pengaruh yang positif bagi konsumen terutama yang mengedepankan prestige serta produk dan pelayanan yang lebih baik dibandingkan dengan hotel level dibawahnya. Konsumen yang merencanakan kunjungan ke Kota terhadap proses keputusan pembelian (Y) sebesar 0,313 atau $31,3 \%$ dan pengaruh positioning (X3) terhadap proses keputusan pembelian (Y) sebesar 0,399 atau $39,9 \%$.

Bandung akan mencari hotel di media elektronik maupun cetak dengan mengedepankan pencarian terhadap klasifikasi hotel dengan level tertentu, contohnya Hotel Bintang 4 Kota Bandung, lalu mencari alternatif pilihan hotel yang sesuai dengan kebutuhannya baik produk maupun pelayanannya, kemudian yang terakhir nama atau brand dari hotel yang akan dipilih kemudian. Oleh karenanya, pada penelitian ini, strategi positioning merupakan faktor yang paling berpengaruh signifikan terhadap proses keputusan pembelian untuk tamu hotel terutama di Kota Bandung.

\section{Pembahasan Verifikatif}

Hubungan kausal antara variabel citra merek, diferensiasi produk dan positioning terhadap proses keputusan pembelian dapat dijelaskan bahwa hubungan variabel $\mathrm{X} 3$ yaitu positioning terhadap variabel $\mathrm{Y}$ yaitu proses keputusan pembelian merupakan hubungan antar variabel dengan nilai korelasi terbesar, sedangkan korelasi terendah antara variabel $\mathrm{X}$ terhadap variabel $Y$ terdapat pada variabel $X 1$ yaitu citra merek terhadap variabel $Y$ yaitu proses keputusan pembelian. Hubungan korelasi antar variabel $\mathrm{X}$ yang tertinggi terdapat pada hubungan korelasi variabel $\mathrm{X} 1$ yaitu citra merek dan variabel X3 yaitu positioning. Hubungan korelasi terendah antar variabel $\mathrm{X}$ terdapat pada hubungan korelasi variabel X2 yaitu diferensiasi produk dan variabel X3 yaitu positioning. Korelasi antara citra merek dan diferensiasi produk terhadap proses keputusan pembelian dapat dikatakan kuat, sedangkan korelasi antara positioning terhadap proses keputusan pembelian dinyatakan sangat kuat.

Hasil uji hipotesis simultan menunjukkan bahwa secara simultan terdapat pengaruh yang signifikan antara citra merek, diferensiasi produk dan 
positioning terhadap proses keputusan pembelian di Hotel Bintang 4 Kota Bandung, terutama yang berada di kawasan Jalan Setiabudhi Bandung. Sedangkan, uji hipotesis parsial menunjukkan bahwa variabel positioning merupakan variabel dengan nilai pengaruh langsung tertinggi, sedangkan pengaruh langsung terendah dalam penelitian ini terdapat pada pengaruh antara citra merek terhadap proses keputusan pembelian. Secara keseluruhan, hasil uji hipotesis menunjukkan bahwa citra merek, diferensiasi produk dan positioning berpengaruh signifikan terhadap proses keputusan pembelian.

Berdasarkan penelitian ini, faktor positioning adalah faktor yang paling berpengaruh terhadap proses keputusan pembelian tamu di Hotel Bintang 4 yang ada di Kota Bandung. Setiap perubahan kecil dalam strategi positioning akan mempengaruhi perubahan keputusan pembelian konsumen. Apabila strategi positioning hotel baik, maka keputusan pembelian konsumen juga akan tinggi, dan sebaliknya apabila strategi positioning hotel buruk, maka keputusan pembelian konsumen juga akan rendah. Perusahaan yang melakukan proses positioning secara relatif akan mampu menghasilkan posisi produk yang jelas dan unggul dalam benak konsumen dibanding dengan pesaingnya.

Melalui perhitungan pengaruh citra merek, diferensiasi produk dan positioning terhadap proses keputusan pembelian secara keseluruhan diperoleh nilai pengaruh sebesar 0,711 atau $71,7 \%$, sedangkan pengaruh dari variabel lain yang tidak diteliti dalam penelitian ini atau variabel epsilon sebesar 0,289 atau 28,9\%. Berdasarkan hasil penelitian tersebut, maka terdapat temuan, bahwa ketiga faktor yaitu citra merek, diferensiasi produk dan positioning merupakan faktor yang layak diteliti karena secara signifikan mempengaruhi proses keputusan pembelian dalam industri perhotelan, khususnya bagi wisatawan yang datang ke Kota Bandung. Namun, sampai saat ini, belum ada teori yang menyebutkan secara langsung bahwa ketiga faktor yaitu citra merek, diferensiasi produk dan positioning merupakan faktor yang mempengaruhi proses keputusan pembelian.

\section{KESIMPULAN}

Berdasarkan hasil penelitian dapat disimpulkan bahwa: (1) Hasil temuan penelitian mengenai tanggapan dari 100 responden yang merupakan tamu yang menginap di Hotel Bintang 4 yang ada di Kota Bandung, diantaranya yaitu Hotel Mercure, Banana Inn Hotel, Grand Setiabudhi Hotel dan Hotel Regata Bandung untuk variabel citra merek, diferensiasi produk dan positioning, serta proses keputusan pembelian di Hotel Bintang 4 Kota Bandung diketahui bahwa secara keseluruhan tanggapan dari 100 orang responden dapat dikategorikan tinggi dilihat dari rata-rata skor yaitu sebesar 3,84 untuk citra merek, sebesar 4,05 untuk diferensiasi produk, dan sebesar 3,83 untuk positioning, serta sebesar 3,84 untuk proses keputusan pembelian; (2) Korelasi antara variabel independen X1 yaitu citra merek terhadap variabel dependen $Y$ yaitu proses keputusan pembelian dikatakan kuat, dengan nilai korelasi sebesar 0,770. Berdasarkan pengujian hipotesis secara simultan maupun partial dinyatakan bahwa variabel citra merek memberikan pengaruh yang signifikan terhadap variabel proses keputusan pembelian; (3) Setiap hotel harus membuat citra yang baik agar dapat mudah diingat oleh pangsa pasar, terutama bagi konsumen atau tamu yang baru pertama kali mencoba produk dan pelayanan hotel tersebut. Dikarenakan persaingan bisnis hotel di Kota Bandung yang saat ini semakin ketat, bagi hotel chain international mungkin hal tersebut akan sangat mudah dilakukan karena hotel dengan merek chain international sudah dikenal masyarakat luar dengan baik. Namun, perlu adanya strategi agar dapat menjaga image hotel tersebut tetap baik dimata konsumennya, diantaranya dengan tetap menjaga kualitas produk dan pelayanan yang diberikan. Citra merek memberikan pengaruh yang signifikan terhadap proses keputusan pembelian, maka pemberian nama hotel 
ataupun pemilihan logo hotel harus dipikirkan dengan matang oleh manajemen hotel agar nama merek dari hotel tersebut dapat dengan mudah dikenal dan diingat oleh konsumennya. Hal yang sederhana seperti pemilihan bentuk logo, pemilihan warna, ukuran text atau font sebaiknya diperhatikan kembali terutama bagi hotel yang baru berkembang. Pemilihan nama dan simbol hotel yang tepat dan mudah dikenal di masyarakat akan membantu menciptakan citra merek yang mudah diingat di benak konsumen.Walaupun tingkat hunian kamar menurun namun seharusnya hal tersebut tidak berpengaruh terhadap kualitas produk terutama pelayanan hotel yang selama ini dinilai baik oleh konsumennya; (4) Korelasi antara variabel independen $\mathrm{X} 2$ yaitu diferensiasi produk terhadap variabel dependen $Y$ yaitu proses keputusan pembelian dikatakan kuat, dengan nilai korelasi sebesar 0,734. Berdasarkan pengujian hipotesis secara simultan maupun partial dinyatakan bahwa variabel diferensiasi produk memberikan pengaruh yang signifikan terhadap variabel proses keputusan pembelian. Walaupun nilai korelasi dari variabel diferensiasi produk adalah yang paling rendah dibandingkan dengan variabel citra merek dan positioning, namun diferensiasi produk dinyatakan sebagai variabel yang berpengaruh signifikan juga terhadap proses keputusan pembelian. Oleh karena itu pemeliharaan dan inovasi terhadap produk hotel harus tetap dilakukan oleh manajemen hotel agar tetap exist di pasar yang kompetitif. Sebaiknya pemugaran dilakukan setiap 2 (dua) tahun sekali, agar hotel tidak terlihat usang. Selain pada fisik bangunan hotel, perbaikan atau pembaharuan juga harus dilakukan terhadap peralatan dan perlengkapan hotel yang biasa dipakai oleh tamu, seperti towl, linen, dan lain sebagainya. Jangan sampai tamu yang sudah datang ke hotel dibuat kecewa dengan mendapatkan pengalaman yang kurang baik terutama untuk kebutuhan dasarnya. Untuk hotel yang program CRMnya sudah berjalan dengan baik, startegi diferensiasi yang dapat dikembangkan bukan hanya dari segi produk saja tetapi juga services nya. Pelayanan seperti mengakomodir kegiatan rekreasi untuk para tamu hotel juga dapat dilakukan oleh bagian pemasaran di hotel. Sehingga apabila ada tamu yang belum mempunyai planning atau rincian kegiatan apa saja yang akan mereka lakukan selama berada di Bandung, dapat dibantu oleh pihak hotel dari mulai perencanaan sampai dengan selesai berwisata. Pihak hotel dapat bekerjasama dengan sejumlah destinasi wisata yang ada di Bandung, seperti Dusun Bambu, Kampung Gajah. Museum 3D Art, Farm House, Trans Studio, dan lain sebagainya dalam menyiapkan konsep wisata tersebut. Dengan adanya bagian yang mengatur kegiatan rekreasi bagi para tamu, tentunya hal tersebut akan menjadi nilai tambah (added value) yang positif bagi pihak hotel di mata konsumennya, dan (5) Korelasi antara variabel independen X3 yaitu positioning terhadap variabel dependen Y yaitu proses keputusan pembelian dinyatakan kuat, dengan nilai korelasi sebesar 0,791. Berdasarkan pengujian hipotesis secara simultan maupun partial dinyatakan bahwa variabel positioning memberikan pengaruh yang signifikan terhadap variabel proses keputusan pembelian. Faktor yang paling berpengaruh signifikan terhadap proses keputusan pembelian bagi tamu hotel Bintang 4 di Kota Bandung adalah positioning, oleh karena itu dalam menentukan target market manajemen harus dapat membedakan pangsa pasar yang mereka tuju agar strategi pemasaran tepat sasaran dan sesuai dengan konsep dan positioning strategy yang mereka terapkan pada hotel. Jangan sampai membidik pangsa pasar yang salah. Bukan hanya terkonsentrasi pada perang harga yang sedang terjadi di bisnis hotel bintang $4 \mathrm{di}$ Kota Bandung seperti saat ini. Strategi menurunkan harga kamar jangan dijadikan solusi alternatif untuk meningkatkan kembali tungkat hunian kamar, tetapi menjaga agar kualitas produk dan pelayanan hotel agar konsisten dengan konsep penempatan posisi hotel harus diutamakan. Terutama untuk standar Hotel Bintang 4, dimana harga jual kamar tidak 
semata-mata ditetapkan agar terjangkau saja oleh pangsa pasar hotel Bintang 3 atau bahkan Bintang 2, tetapi juga harus mempertimbangkan faktor positioning sebagai Hotel Bintang 4 agar persepsi konsumen tidak turun terhadap kualitas produk dan pelayanan dari Hotel Bintang 4 yang sudah lebih terjamin dibandingkan Hotel Bintang 3 atau 2 sebelumnya. Agar pangsa pasar yang dituju akan dengan mudah mengambil keputusan untuk membeli dan menginap di hotel yang kita tawarkan, maka hal-hal di atas, yaitu citra merek, diferensiasi produk dan positioning harus diperhatikan oleh manajemen hotel. Menjaga agar citra merek tidak pudar dan berkurang dimata pangsa pasar merupakan salah satu strategi yang harus dilakukan oleh manajemen hotel terutama Hotel Bintang 4 di kawasan Setiabudhi Kota Bandung. Pemeliharaan terhadap fisik bangunan hotel juga harus diperhatikan. Setiap tamu yang menginap di hotel juga harus dimintai komentarnya dengan membagikan guest comment di setiap kamar. Hal ini banyak dilakukan oleh beberapa hotel tetapi kesinambungannya juga kurang diperhatikan. Jangan sampai kegiatan tersebut putus ditengah jalan, sehingga apa saja yang dibutuhkan tamu hotel dapat mengetahui dan berusaha untuk menyediakannya kembali. Hal ini berlaku untuk semua hotel, terutama untuk hotel dengan kelas Bintang 4.

\section{DAFTAR PUSTAKA}

Arikunto, S. (2006). Prosedur Penelitian Suatu Pendekatan Praktik. Jakarta: Rineka Cipta.

Basu, S., \& Irawan. (2008). Manajemen Pemasaran Modern. Yogyakarta: Liberty.

Dewi, N.L.G.D.N., \& Jatra, M. (2013). Pengaruh Atribut Produk Terhadap Keputusan Pembelian Handphone Di Kota Denpasar. E-Jurnal Manajemen Universitas Udayana, 3(6), h: 248-261.
Ferrinadewi, E. (2008). Merek \& Psikologi Konsumen. Yogyakarta: Graha Ilmu.

Kotler, B., \& Makens, J. (2002). Pemasaran Perhotelan dan Kepariwisataan. Edisi Kedua. Jakarta: PT. Prenhallindo.

Kotler, P. (2005). Manajemen Pemasaran. Jilid 1. Jakarta: PT. Indeks Kelompok Gramedia.

Kotler, P., \& Keller, K.L. (2007). Manajemen Pemasaran. Jilid 1 Edisi 12. Jakarta: PT. Indeks.

Mayliana \& Febriansyah. (2013). Analisis Pengaruh Positioning, Diferensiasi Dan Ekuitasmerek Terhadap Keputusan Pembelian Pada Produk Kuku Bima Ener-G. Jurnal Manajemen dan Bisnis Volume 17, Nomor 2, Desember 2013, hlm.132- 144.

Nazir, M. (2011). Metode Penelitian Pendidikan. Ciawi-Bogor: Ghalia Indonesia.

Silalahi, U. (2009). Metode Penelitian Sosial. Bandung: PT. Refika Aditama.

Simamora, I.K., Handoyo, D.W., \& Widiyanto. (2013). Pengaruh Harga, Citra Merek, Positioning dan Diferensiasi Produk Terhadap Keputusan Pembelian Konsumen Pada Produk Jamu PT. Njonja Meneer. Diponegoro Journal of Social and Politic, h: 1-12. http://ejournals1.undip.ac.id/index.php/

Sudjana. (2005). Metoda Statistika. Bandung: PT. Tarsito Bandung.

Sugiyono.(2010). Metode Penelitian Kuantitatif, Kualitatif \& RND. Bandung: Alfabeta.

--------. (2013). Statistika Untuk Penelitian. Bandung: Alfabeta.

Surachman, S.A.(2008). Dasar-dasar Manajemen Merek. Malang: CV. Banyumedia.

Swastha, B., \& Irawan. (2008). Manajemen Pemasaran Modern. Yogyakarta: Liberty Yogyakarta. 